Incidence of Oxacillin-Susceptible mecA-Positive Staphylococcus

\title{
aureus (OS-MRSA) Isolates and TSST-1 Virulence Factor Among High School Students in Tabriz, Northwest of Iran
}

\author{
Sahar Zeinalpour Ahrabi ${ }^{1}$, Leila Rahbarnia ${ }^{2,}{ }^{*}$, Alireza Dehnad ${ }^{3}$, Behrooz Naghili ${ }^{2}$, Mohammad \\ Hossein Ghaffari Agdam ${ }^{2}$ and Atefeh Nazari ${ }^{2}$ \\ ${ }^{1}$ Higher Education Institute of Rab-Rashid, Tabriz, Iran \\ ${ }^{2}$ Infectious and Tropical Diseases Research Center, Tabriz University of Medical Sciences, Tabriz, Iran \\ ${ }^{3}$ Biotechnology Department, East Azerbaijan Research and Education Canter Agricultural and Natural Resources, AREEO, Tabriz, Iran \\ "Corresponding author: Infectious and Tropical Diseases Research Center, Tabriz University of Medical Sciences, Tabriz, Iran. Email: le.rahbarnia@gmail.com
}

Received 2018 October 14; Revised 2019 July 15; Accepted 2019 July 28.

\begin{abstract}
Background: Methicillin-resistant Staphylococcus aureus (MRSA) is often the cause of a wide broad of infections ranging from minor skin infections to serious infections such as toxic shock syndrome (TSS) in hospital and community settings. Toxic shock syndrome toxin 1 (TSST-1) superantigen is the main cause of TSS.

Objectives: The current study aimed to determine the frequency of MRSA carriage and TSST-1 virulence factor among high school students.

Methods: A total of 400 nasal swab samples were randomly collected from male and female students of six different high schools in Tabriz, Iran. After confirmation of S. aureus strains by standard biochemical tests, the antibiotic sensitivity pattern of the isolates was determined by the disk diffusion method. The presence of mecA and TSST-1 genes was examined by PCR.

Results: From 400 students, $15 \%(n=60)$ were positive for S. aureus. Antimicrobial susceptibility testing was performed using 12 antibiotic disks. Based on the results, $100 \%$ of the isolates were resistant to ampicillin while all of them were sensitive to vancomycin. Moreover, $18.34 \%$ of the S. aureus isolates were resistant to cefoxitin and $11.67 \%$ were resistant to oxacillin. The presence of the mecA gene was confirmed in $54.54 \%$ of the cases. These results indicated oxacillin-susceptible mecA-positive S. aureus (OS-MRSA) colonization among students. Based on the PCR results, only one of the MRSA isolates belonging to a female student was positive for the TSST-1 gene.

Conclusions: Our findings highlight the spread of OS-MRSA among the healthy population in Tabriz, Northwest of Iran. Nevertheless, a combination of genetic and phenotypic tests is needed to accurately detect MRSA.

Keywords: Staphylococcus aureus, MRSA, mecA, TSST-1, High School Students
\end{abstract}

\section{Background}

Staphylococcus aureus (S. aureus) as a Gram-positive pathogen is known as the main cause of infections ranging from minor skin infections to serious infections including osteomyelitis, bacteremia, infective endocarditis, necrotizing pneumonia, and toxic shock syndrome (TSS) (1). There are several virulence factors in S. aureus including cell surface virulence factors (capsular polysaccharides), exoproteins (cytolysins), and superantigens (TSST-1)(2). Superantigens are responsible for a number of human diseases such as food poisoning and TSS. These bacterial toxins can activate $\mathrm{T}$ cell receptor (TCR), immunoreceptors, major histocompatibility complex (MHC) class II, and re- lease cytokines (3).

TSS is a polysystemic disease with symptoms including hypotension, fever, shock, skin rash, and skin peeling. The cause of TSS in most individuals with wound infection is the MRSA colonization (4). Based on recent reports, there is a direct relationship between the use of tampon by women and the incidence of TSS in the healthy population (3). Conventionally, $S$. aureus colonization occurs in different parts of the body such as perineal, axillary, and nasal regions called the nasal carriage of S. aureus (5).

The colonization of S. aureus is not often the main reason for infection; however, it is a known risk factor for the emergence of subsequent infections so that it can act as a reservoir of clinical infections in colonized individuals (6, 
7).

At present, the appearance of antibiotic-resistant S. aureus strains called methicillin-resistant S. aureus (MRSA) has been known as a serious threat in hospital and community settings. MRSA infections are mostly associated with high morbidity and mortality and the increased length of hospital stay, particularly in individuals with HIV, cancer, rheumatoid arthritis, and diabetes (8).

The mecA gene in Staphylococcus species is responsible for resistance to methicillin. It is located on chromosomal cassette mec and encodes a low-affinity penicillin-binding protein (PBP2a). Therefore, the MRSA strains are resistant to all beta-lactam antibiotics $(9,10)$. In recent years, novel MRSA strains have emerged as oxacillin-susceptible mecApositive $S$. aureus (OS-MRSA) strains that carry the mecA gene but are sensitive to oxacillin; thus, they could be wrongly identified as MSSA (11). At present, the spread of the OS-MRSA isolates is considered to be due to their misidentification as MSSA and treatment failure with $\beta$ lactam antibiotics (12).

\section{Objectives}

This study aimed to isolate OS-MRSA and identify the Tsst-1 virulence factor among high school students.

\section{Methods}

\subsection{Bacteria Identification}

The nasal swab samples were obtained from 400 randomly selected healthy students (200 boys and 200 girls) from six different high schools in Tabriz city from January1, 2018, to March 1, 2018. The obtained samples were cultured in selective media (blood agar and mannitol salt agar) and incubated overnight at $37^{\circ} \mathrm{C}$. S. aureus strains were identified by conventional microbiological and biochemical methods (colony morphology, Gram staining, catalase test, and coagulase test) (13).

\subsection{Antimicrobial Susceptibility Testing}

The susceptibility pattern of the isolates was determined using 12 antibiotics based on the Kirby Bauer disk diffusion method following the Clinical Laboratory Standards Institute (CLSI) guidelines (10). The methicillin sensitivity test was carried out based on resistance to cefoxitin (30 $\mu \mathrm{g} /$ disc). The used antibiotic disks were as follows: erythromycin (15 $\mu \mathrm{g})$, chloramphenicol (30 $\mu \mathrm{g})$, oxacillin $(1 \mu \mathrm{g})$, ciprofloxacin $(5 \mu \mathrm{g})$, clindamycin $(2 \mu \mathrm{g})$, penicillin (6 $\mu \mathrm{g})$, amoxicillin/clavulanic acid $(20 / 10 \mu \mathrm{g})$, cefazolin (30 $\mu \mathrm{g})$, vancomycin (30 $\mu \mathrm{g})$, cefoxitin (30 $\mu \mathrm{g})$, ampicillin (10 $\mu \mathrm{g})$, and novobiocin ( $5 \mu \mathrm{g})$. To perform the disk diffusion test, bacterial concentrations equal to 0.5 McFarland were prepared to inoculate Muller-Hinton agar plats. The antibiotic disks were incubated with the inoculated plates at $37^{\circ} \mathrm{C}$ overnight. All antibiotics were produced by Biomaxima (Poland).

\subsection{Primer Designing}

The specific primers of TSST- 1 and mecA genes were designed using Gene Runner software based on the S. aureus genome sequences available in the Gene Bank database. The specificity of the designed primers was evaluated using Primer-BLAST.

\subsection{DNA Extraction and PCR Amplification}

DNA was extracted from individual colonies using the boiling method. In this method, pure colonies were suspended in $300 \mu \mathrm{L}$ of TE buffer (10 mM Tris, $1 \mathrm{mM}$ EDTA); then, cell suspensions were boiled at $95^{\circ} \mathrm{C}$ and centrifuged. The quantification of the extracted DNA was carried out via spectroscopy at $260 \mathrm{~nm}$. The DNA purity was determined by the ratio of absorbance at $260 / 280$. Then, the PCR was carried out to examine the presence of mecA and TSST-1 genes using specific primers (Table 1). The PCR products were analyzed by the agarose gel electrophoresis. For further corroboration, the PCR product of each gene was analyzed by sequencing.

\section{Results}

\subsection{Bacterial Identification}

In total, 400 nasal samples were obtained from male and female students of six different high schools in Tabriz. Based on the results, 60 (15\%) students were positive for $S$. aureus; 9.5\% (38/400) of the S. aureus-positive isolates belonged to male students and 5.5\% (22/400) to female students. The statistical analysis showed that the frequency of S. aureus was dependent on gender $(\mathrm{P}<0.05)$.

\subsection{Antimicrobial Susceptibility}

The antibiotic resistance patterns were determined using 12 antibiotics by the disc diffusion method. All S. aureus isolates were resistant to ampicillin and $98.33 \%$ to penicillin. All of the 60 isolates were sensitive to vancomycin. Based on the results, $18.34 \%$ (11/60) of the isolates were resistant to cefoxitin (MRSA) and 11.67\% (7/60) were resistant to oxacillin. The results are summarized in Table 2. From 60 S. aureus-positive strains, 19 (31.66\%) showed multi-drug resistant (MDR) property. A significant correlation was observed between the presence of the mecA gene and resistance to ampicillin, penicillin, oxacillin, ciprofloxacin, erythromycin, cefoxitin, and amoxicillin/clavulanic acid ( $\mathrm{P}<$ $0.05)$. 


\begin{tabular}{|c|c|c|c|c|}
\hline Primer & Primer Sequence $\left(5^{\prime} \rightarrow 3^{\prime}\right)$ & Temperature, ${ }^{\circ} \mathrm{C}$ & Cycle No. & Size, bp \\
\hline \multirow[t]{2}{*}{ mecA } & F:5'-AGAAATGACTGAACGTCC-3' & 48 & 35 & 305 \\
\hline & R:5'-ATTCCACATTGTTTCGGTC-3' & & & \\
\hline \multirow[t]{2}{*}{ TSST-1 } & F: 5'-ACAAGCGCTATTTTTATTTCAG-3' & 49 & 30 & 271 \\
\hline & R: 5'-СССАТССССААССАСТTТT-3' & & & \\
\hline
\end{tabular}

\begin{tabular}{lccc}
\hline Table 2. Results of Antimicrobial Susceptibility Testing by the Disk Diffusion Method \\
\hline Antibiotics & Resistant, \% & Intermediate, \% & Sensitive, \% \\
\hline Erythromycin & 18.34 & 10 & 71.66 \\
\hline Chloramphenicol & 3.33 & 3.33 & 93.34 \\
\hline Oxacillin & 11.67 & 1.66 & 86.67 \\
\hline Ciprofloxacin & 5 & 26.67 & 68.33 \\
\hline Clindamycin & 6.67 & 3.33 & 90 \\
\hline Ampicillin & 100 & - & - \\
\hline $\begin{array}{l}\text { Amoxicillin/clavulanic } \\
\text { acid }\end{array}$ & 36.67 & - & 63.33 \\
\hline Penicillin & 98.33 & - & 1.67 \\
\hline Cefoxitin & 18.34 & - & 81.66 \\
\hline Cefazolin & 5 & 1.67 & 93.33 \\
\hline Vancomycin & - & - & 100 \\
\hline
\end{tabular}

\subsection{Detection of mecA and TSST-1 Genes by PCR}

The results of the PCR assay performed on S. aureus isolates showed that $54.54 \%$ (36/60) of the strains were positive for the mecA gene (Figure 1) while only $11.67 \%$ were resistant to oxacillin. These results indicate the emergence of OS-MRSA for the first time in the healthy population of Iran. Based on the results of PCR, the TSST-1 gene was detected as an expected band of 271 bp (Figure 2) only in $1.5 \%$ (one sample) of the strains from an MRSA isolate belonging to a girl student.

\subsection{Sequencing Analysis}

Since the TSST-1-positive strain was the first report in the study region, the sequence was amplified by TSST-1 specific primers, subjected to sequencing, and analyzed by NCBI BLAST. The results showed that the TSST-1-positive isolate had $100 \%$ homology to the TSST-1 gene previously reported in an S. aureus strain (Sequence ID: AB084255.1).

\section{Discussion}

In the last two decades, the epidemiology of MRSA infections has changed from healthcare-associated (HA)MRSA to community-associated (CA)-MRSA as a causative agent of infection in clinical settings (14-16). On the other hand, the prevalence of MRSA infections has emerged as a serious problem since MRSA strains are resistant to most antibiotics, particularly $\beta$-lactams. Based on recent studies, the nasal colonization of $S$. aureus plays a major role in the pathogenesis and epidemiology of infections (17). At present, the prevalence of the MRSA nasal carriage is increasing in the healthy population. For instance, in a study performed in Jordan, the frequency of the MRSA nasal carriage was $7.5 \%$ in a healthy population (18). In a similar study conducted in Western Nepal, 32 out of 204 (15.7\%) healthcare workers were S. aureus carriers, of which $21.9 \%$ (7 cases) were MRSA(19). In the present study, the frequency of nasal carriage of $S$. aureus was examined in a healthy population. Based on the results, 60 out of 400 (15\%) students were nasal carriers of S. aureus and 2.18\% (11/400) of the students were MRSA-positive based on the phenotypic test.

Our results are consistent with previous results reported by Khanal et al. in 2015 that highlighted the MRSA nasal carriage rate of 3.4\% (7/204) among health care workers in Western Nepal (19). In the present study, $18.34 \%$ of the S. aureus-positive samples were resistant to erythromycin and cefoxitin and $11.67 \%$ were resistant to oxacillin. These findings are not consistent with a previous study of nasal carriers of $S$. aureus in nursing students that reported the rate of S. aureus positivity as $32.5 \%$, MRSA as $10 \%$, and resistance to erythromycin as 30\% (20). According to our results, $6.67 \%$ of the isolates were resistant to clindamycin that contradicts the findings of da Silva et al. in Pernambuco; they assessed resistance to clindamycin among nursing staff in a teaching hospital and reported that $11.9 \%$ of the nasal carriers were resistant to clindamycin (21). Currently, a notable increase is reported in the prevalence of MDR among MRSA isolates that imposes a serious menace on public health (22).

In the present study, from $60 \mathrm{~S}$. aureus-positive isolates, 31.66\% (19 cases) were MDR-positive. This result is consistent with a previous study in Kashan, Iran, that reported $26.3 \%$ of healthy children were nasal carriers of S. aureus, 29.3\% were MDR-positive, and 35.9\% were MRSA-positive (23).

The results of PCR indicated that the mecA gene was 


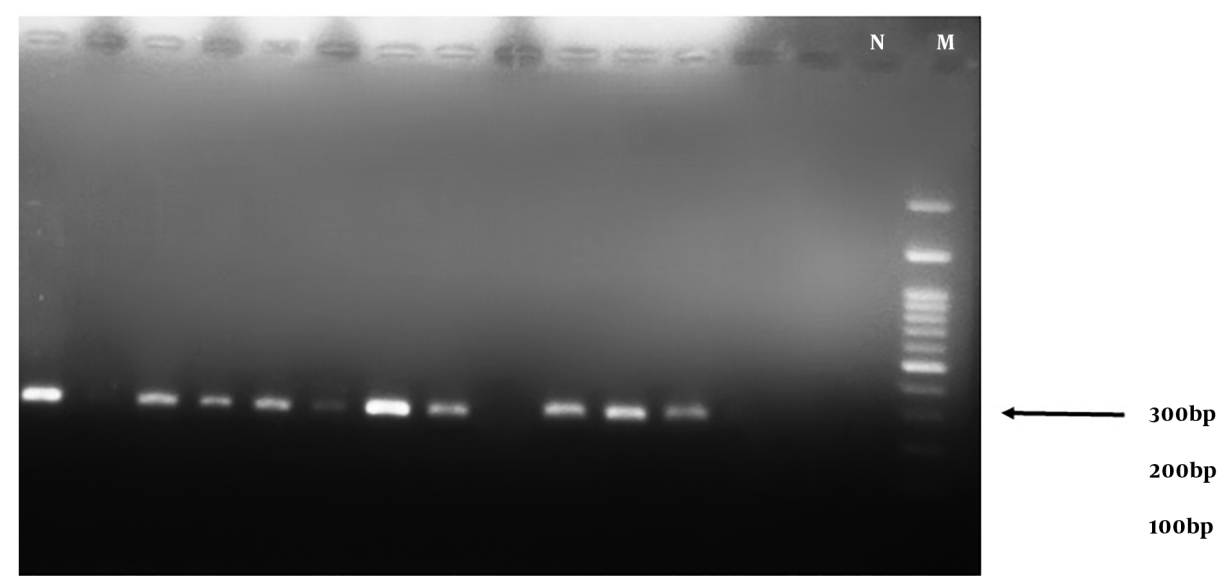

Figure 1. PCR Amplification of mecA gene fragment by specific primers as a sharp band of 305 bp upon electrophoresis

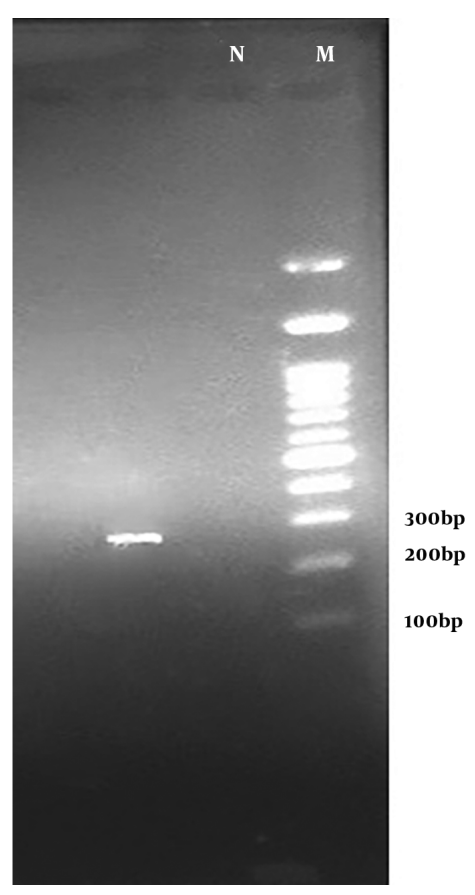

Figure 2. Results of PCR of TSST-1 gene fragment by specific primers as a single band of 271 bp upon electrophoresis

present in 54.54\% (36/60) of the S. aureus isolates while only $11.67 \%$ of the S. aureus isolates were resistant to oxacillin. As a result, $6.25 \%$ of the students were OS-MRSA carriers. These results indicate the increasing prevalence of OS-MRSAs in the healthy population of Iran concerning the results of a study performed in 2013 on 173 nurses in Iran that reported $4.6 \%$ of the cases were MRSA carriers and only $1.15 \%$ of the MRSA isolates were OS-MRSA (24). In a study performed on healthcare workers in two African countries, $2.4 \%$ of the individuals were OS-MRSA carriers that can transfer it to patients as the reservoirs of OS-MRSA (25). Recent studies indicate an increase in the prevalence of oxacillinsusceptible mecA-positive $S$. aureus in human infections $(26,27)$.

Since OS-MRSA isolates carry the mecA gene but are sensitive to oxacillin, they could be wrongly identified as MSSA if the detection of the mecA gene is not tried (28). In the present study, one of the isolates (1.5\%), which was an MRSAMDR strain, was positive for the TSST-1 gene. This result is consistent with the results by Hogan et al. in 2016 regarding the detection of the TSST-1 gene among students in Madagascar in which, $1.9 \%$ of the students were positive for the TSST-1 gene (29).

\subsection{Conclusions}

Our findings highlight a high prevalence of OS-MRSA in high school students of Tabriz, Northwest of Iran. Nevertheless, the combination of genetic and phenotypic tests could be essential to accurately detect MRSA.

\subsection{Limitations}

This study did not examine the molecular characteristics of OS-MRSA and TSST-1-positive MRSA strains.

\section{Acknowledgments}

This study was supported by the Infectious and Tropical Diseases Research Center, Tabriz University of Medical Sciences, Tabriz, Iran. 


\section{Footnotes}

Authors' Contribution: All authors read and approved the final manuscript.

Conflicts of Interests: The authors have no conflicts of interest.

Ethical Approval: The study was conducted after obtaining the ethical approval from the Ethics Committee of Tabriz University of Medical Sciences, Tabriz Iran (reference number: IR. TBZMED. REC.1397.448).

Funding/Support: This research received no specific grants from funding agency.

Patient Consent: Data and swab samples were collected after obtaining the written consent of the participants and presenting a brief description of the importance of the study.

\section{References}

1. Lin YC, Peterson ML. New insights into the prevention of staphylococcal infections and toxic shock syndrome. Expert Rev Clin Pharmacol. 2010;3(6):753-67. doi: 10.1586/ecp.10.121. [PubMed: 21625323]. [PubMed Central: PMC3102526].

2. Bernal A, Proft T, Fraser JD, Posnett DN. Superantigens in human disease. J Clin Immunol.1999;19(3):149-57. [PubMed: 10404399].

3. Saline M, Rodstrom KE, Fischer G, Orekhov VY, Karlsson BG, LindkvistPetersson K. The structure of superantigen complexed with TCR and MHC reveals novel insights into superantigenic T cell activation. Nat Commun. 2010;1:119. doi: 10.1038/ncomms1117. [PubMed: 21081917].

4. Reddy PN, Srirama K, Dirisala VR. An update on clinical burden, diagnostic tools, and therapeutic options of Staphylococcus aureus. Infect Dis (Auckl). 2017;10:1.179916117704E+15. doi: 10.1177/1179916117703999. [PubMed: 28579798]. [PubMed Central: PMC5443039].

5. Karabay O. Nasal carriage frequency of Staphylococcus aureus according to education years of medical students. J Microbiol Infect Dis. 2016;6(3):103-6. doi: 10.5799/jmid.328963.

6. Davoodabadi F, Mobasherizadeh S, Mostafavizadeh K, Shojaei H, Havaei SA, Koushki AM, et al. Nasal colonization in children with community acquired methicillin-resistant Staphylococcus aureus. Adv Biomed Res. 2016;5:86. doi: 10.4103/2277-9175.182217. [PubMed: 27274501]. [PubMed Central: PMC4879855].

7. Pathak A, Marothi Y, Iyer RV, Singh B, Sharma M, Eriksson B, et al. Nasal carriage and antimicrobial susceptibility of Staphylococcus aureus in healthy preschool children in Ujjain, India. BMC Pediatr. 2010;10:100. doi: 10.1186/1471-2431-10-100. [PubMed: 21190550] [PubMed Central: PMC3022789].

8. Raygada JL, Levine DP. Methicillin-resistant Staphylococcus aureus: A growing risk in the hospital and in the community. Am Health Drug Benefits. 2009;2(2):86-95. [PubMed: 25126276]. [PubMed Central: PMC4115307].

9. Fuda C, Suvorov M, Vakulenko SB, Mobashery S. The basis for resistance to beta-lactam antibiotics by penicillin-binding protein 2a of methicillin-resistant Staphylococcus aureus. $J$ Biol Chem. 2004;279(39):40802-6. doi: 10.1074/jbc.M403589200. [PubMed: 15226303]

10. Nathwani D, Morgan M, Masterton RG, Dryden M, Cookson BD, French $\mathrm{G}$, et al. Guidelines for UK practice for the diagnosis and management of methicillin-resistant Staphylococcus aureus (MRSA) infections presenting in the community. J Antimicrob Chemother. 2008;61(5):976-94 doi: 10.1093/jac/dkn096. [PubMed: 18339633].
11. Labrou M, Michail G, Ntokou E, Pittaras TE, Pournaras S, Tsakris A. Activity of oxacillin versus that of vancomycin against oxacillinsusceptible mecA-positive Staphylococcus aureus clinical isolates evaluated by population analyses, time-kill assays, and a murine thigh infection model. Antimicrob Agents Chemother. 2012;56(6):338891. doi: 10.1128/AAC.00103-12. [PubMed: 22430957]. [PubMed Central: PMC3370787].

12. Pournaras S, Stathopoulos C, Tsakris A. Oxacillin-susceptible MRSA: Could it become a successful MRSA type? Future Microbiol. 2013;8(11):1365-7. doi: 10.2217/fmb.13.118. [PubMed: 24199795].

13. Zarei Koosha R, Mahmoodzadeh Hosseini H, Mehdizadeh Aghdam E, Ghorbani Tajandareh S, Imani Fooladi AA. Distribution of tsst-1 and mecA genes in Staphylococcus aureus isolated from clinical specimens. Jundishapur J Microbiol. 2016;9(3). e29057. doi: 10.5812/jjm.29057. [PubMed: 27226873]. [PubMed Central: PMC4876617].

14. Gomez P, Gonzalez-Barrio D, Benito D, Garcia JT, Vinuela J, Zarazaga $M$, et al. Detection of methicillin-resistant Staphylococcus aureus (MRSA) carrying the mecC gene in wild small mammals in Spain. J Antimicrob Chemother. 2014;69(8):2061-4. doi: 10.1093/jac/dku100. [PubMed: 24710026].

15. Tong SY, Davis JS, Eichenberger E, Holland TL, Fowler VJ. Staphylococcus aureus infections: epidemiology, pathophysiology, clinical manifestations, and management. Clin Microbiol Rev. 2015;28(3):60361. doi: 10.1128/CMR.00134-14. [PubMed: 26016486]. [PubMed Central: PMC4451395].

16. Baba T, Takeuchi F, Kuroda M, Yuzawa H, Aoki K, Oguchi A, et al. Genome and virulence determinants of high virulence communityacquired MRSA. Lancet. 2002;359(9320):1819-27. doi: 10.1016/s01406736(02)08713-5. [PubMed: 12044378].

17. El Aila NA, Al Laham NA, Ayesh BM. Nasal carriage of methicillin resistant Staphylococcus aureus among health care workers at Al Shifa Hospital in Gaza Strip. BMC Infect Dis. 2017;17(1):28. doi: 10.1186/s12879016-2139-1. [PubMed: 28056831]. [PubMed Central: PMC5217237].

18. Al-Bakri AG, Al-Hadithi H, Kasabri V, Othman G, Kriegeskorte A, Becker K. The epidemiology and molecular characterization of methicillin-resistant staphylococci sampled from a healthy Jordanian population. Epidemiol Infect. 2013;141(11):2384-91. doi: 10.1017/S0950268813000010. [PubMed: 23340022].

19. Khanal R, Sah P, Lamichhane P, Lamsal A, Upadhaya S, Pahwa VK. Nasal carriage of methicillin resistant Staphylococcus aureus among health care workers at a tertiary care hospital in Western Nepal. Antimicrob Resist Infect Control. 2015;4:39. doi: 10.1186/s13756-015-0082-3. [PubMed: 26457182]. [PubMed Central: PMC4600207].

20. Marino C, Marcatto JT, Gushiken CY, Lima RS, Moris DV, Rodrigues MVP. Evaluation of Staphylococcus aureus resistance profile isolated from nursing students in an institution of higher education. Acta Scientiarum Health Sci. 2016;38(2):145. doi: 10.4025/actascihealthsci.v38i2.29409.

21. da Silva EC, Samico TM, Cardoso RR, Rabelo MA, Bezerra Neto AM, de Melo FL, et al. [Colonization by Staphylococcus aureus among the nursing staff of a teaching hospital in Pernambuco]. Rev Esc Enferm USP. 2012;46(1):132-7. Portuguese. [PubMed: 22441276].

22. Garoy EY, Gebreab YB, Achila OO, Tekeste DG, Kesete R, Ghirmay $\mathrm{R}$, et al. Methicillin-resistant Staphylococcus aureus (MRSA): Prevalence and antimicrobial sensitivity pattern among patients-a multicenter study in Asmara, Eritrea. Can J Infect Dis Med Microbiol. 2019;2019:8321834. doi: 10.1155/2019/8321834. [PubMed: 30881532]. [PubMed Central: PMC6381584].

23. Erami M, Soltani B, Taghavi Ardakani A, Moravveji A, Haji Rezaei $M$, Soltani S, et al. Nasal carriage and resistance pattern of multidrug resistant Staphylococcus aureus among healthy children in Kashan, Iran. Iran Red Crescent Med J. 2014;16(9). e21346. doi:10.5812/ircmj.21346. [PubMed: 25593734]. [PubMed Central: PMC4270649]. 
24. Jannati E, Arzanlou M, Habibzadeh S, Mohammadi S, Ahadi P, Mohammadi-Ghalehbin B, et al. Nasal colonization of mecA-positive, oxacillin-susceptible, methicillin-resistant Staphylococcus aureus isolates among nursing staff in an Iranian teaching hospital. Am J Infect Control. 2013;41(11):1122-4. doi: 10.1016/j.ajic.2013.02.012. [PubMed: 23706805].

25. Conceicao T, Coelho C, de Lencastre H, Aires-de-Sousa M. Frequent occurrence of oxacillin-susceptible mecA-positive Staphylococcus aureus (OS-MRSA) strains in two African countries. J Antimicrob Chemother. 2015;70(12):3200-4. doi: 10.1093/jac/dkv261. [PubMed: 26318189].

26. Kumar VA, Steffy K, Chatterjee M, Sugumar M, Dinesh KR, Manoharan A, et al. Detection of oxacillin-susceptible mecA-positive Staphylococcus aureus isolates by use of chromogenic medium MRSA ID. J Clin Microbiol. 2013;51(1):318-9. doi: 10.1128/JCM.01040-12. [PubMed: 23135944]. [PubMed Central: PMC3536263].

27. Mistry H, Sharma P, Mahato S, Saravanan R, Kumar PA, Bhan- dari V. Prevalence and characterization of oxacillin susceptible mecA-positive clinical isolates of Staphylococcus aureus causing bovine mastitis in India. PLoS One. 2016;11(9). e0162256. doi: 10.1371/journal.pone.0162256. [PubMed: 27603123]. [PubMed Central: PMC5014444].

28. Pu W, Su Y, Li J, Li C, Yang Z, Deng H, et al. High incidence of oxacillinsusceptible mecA-positive Staphylococcus aureus (OS-MRSA) associated with bovine mastitis in China. PLoS One. 2014;9(2). e88134. doi: 10.1371/journal.pone.0088134. [PubMed: 24523877]. [PubMed Central: PMC3921137].

29. Hogan B, Rakotozandrindrainy R, Al-Emran H, Dekker D, Hahn A, Jaeger A, et al. Prevalence of nasal colonisation by methicillinsensitive and methicillin-resistant Staphylococcus aureus among healthcare workers and students in Madagascar. BMC Infect Dis. 2016;16(1):420. doi: 10.1186/s12879-016-1733-6. [PubMed: 27526771]. [PubMed Central: PMC4986198]. 